\title{
Extraction Optimization, Structural Characterization, and Anti-Hepatoma Activity of Polysaccharides from Scutellaria Barbata D. Don
}

\section{Wenwen Su}

Mudanjiang Medical University

\section{Leilei Wu}

Mudanjiang Medical University

Qichao Liang

Mudanjiang Medical University

Xiaoyue Lin

Heilongjiang University of Chinese Medicine

Xiaoyi Xu

Mudanjiang Medicai University

Shikai Yu

Heilongjiang University of Chinese Medicine

Yitong Lin

Mudanjiang Medical University

\section{Yang Fu}

Mudanjiang Medical University

Jiadong Zhou

Mudanjiang Medical University

\section{Bo Zhang}

Mudanjiang Cancer Hospital

\section{Li Li}

Mudanjiang Medical University

Dan Li

Mudanjiang Medical University

\section{Yongkui Yin}

Mudanjiang Medical University

Gaochen Song ( $\nabla$ songgaochen32@sina.com )

Mudanjiang Medical University 
Keywords: Polysaccharides from Scutellaria barbata D. Don, Separation, Anti-hepatoma activity

Posted Date: November 2nd, 2021

DOI: https://doi.org/10.21203/rs.3.rs-1018191/v1

License: (c) (1) This work is licensed under a Creative Commons Attribution 4.0 International License. Read Full License 


\section{Abstract}

Background The above experimental results show that SBP-2A isolated and purified from Scutellaria barbata may be a candidate drug for further evaluation in cancer prevention, which provides a clue for further studies on the molecular mechanism of its anticancer activity against human liver cancer cells.

Methods The crude polysaccharide of Scutellaria barbata (SBP) was extracted with water and precipitated with alcohol. Optimal extraction conditions were determined by response surface methodology: the solid-liquid ratio was 1:25, the extraction time was $2 \mathrm{~h}$, and the extraction temperature was $90^{\circ} \mathrm{C}$. With these conditions, the average extraction efficiency was $3.85 \pm 0.13 \%$. SBP was purified with a DEAE-52 cellulose column and Sephadex G-100 dextran gel column to obtain SBP-1A and SBP-2A fractions. The polysaccharide content, molecular weight, monosaccharide composition and basic structure were preliminarily identified. Then, a MTT assay was used to identify the polysaccharide components with anti-hepatoma effects. The antitumor activity of SBP-2A was evaluated by colony formation tests, morphological observations, apoptosis and cell cycle analyses.

Results Structural analysis showed that SBP-1A and SBP-2A were mainly composed of arabinose and galactose, but the molar ratios were different; these were homogeneous acidic polysaccharide components with high purity, and the average molecular weights were $1.15 \times 10^{5} \mathrm{Da}$ and $1.4 \times 10^{5} \mathrm{Da}$, respectively. FT-IR spectra showed that SBP-1A and SBP-2A contained uronic acid $\beta$-glucan, and the sugar residue of the polysaccharide was mainly pyranose. MTT and colony formation assays showed that SBP2A significantly inhibited the proliferation of HepG2 cells. The cell distribution at different apoptotic stages was determined by the Hoechst 33258 test and Annexin V-FITC/PI staining. Flow cytometric analysis showed that SBP-2A induced HepG2 cell apoptosis by blocking the G1 phase.

Conclusions Two polysaccharides (SBP-1A and SBP-2A) had been isolated from Scutellaria barbata. Preliminary characterization of the SBP-1A and SBP-2A was investigated. The anticancer activities were studied in vitro. SBP-2A significantly inhibited the proliferation of HepG2 cells and induced cells apoptosis by blocking the $\mathrm{G} 1$ phase.

\section{Background}

Liver cancer is the fourth leading cause of cancer deaths and ranks sixth among new cases in the world(1). Because of its early silence and high heterogeneity, most patients with liver cancer are diagnosed in the late stages, and the cure rate is low. According to current trends, the number of new cases and deaths due to liver cancer worldwide are expected to increase from 841,080 and 781,631 in 2018 to $1,361,836$ and $1,284,252$ in 2040 , which constitute increases of $62 \%$ and $64 \%$, respectively(2). The methods for treating liver cancer include surgical resection, liver transplantation, arterial chemoembolization, and systemic pharmacological treatment with kinase inhibitors such as sorafenib. However, nearly $70 \%$ of patients easily develop recurrent liver cancer or metachronous liver cancer(3), which also causes typical side effects such as hypertension, hypothyroidism, and 
leucopenia/neutropenia(4). Compared with the burdens of many other major cancers, although the incidence and mortality rates for liver cancer are increasing worldwide, the development of new drugs for liver cancer has historically been lacking. Therefore, the development of low toxicity and high-efficiency antitumor drugs has become the focus of researchers.

Many studies have shown that polysaccharides used in Chinese medicine have attracted interest in the field of natural macromolecules because of their significant biological activities, which include antitumor(5), antioxidant(6) and anticoagulant activities(7), and treatment applications for ischemiareperfusion injury(8), liver protection(9), viral infections(10), control of blood lipids(11), control of blood pressure(12) and immune regulation(13). Scutellaria barbata D. Don is a plant of the family Lamiaceae(14), is listed in the 2015 edition of the Chinese Pharmacopoeia and has the unique effects of clearing away heat and toxic material, diuresis and detumescence. Recent pharmacological studies have provided strong evidence for antitumor, antioxidant, antibacterial, antiviral and immunomodulatory effects(15-17), and these medicinal values are attributed to the fact that Scutellaria barbata contains a variety of components, including alkaloids, flavonoids, steroids and polysaccharides(18). As high molecular weight carbohydrates, polysaccharides are very important in the life activities of organisms. Scutellaria barbata polysaccharide can resist complement(19), inhibit the growth of lung cancer(20, 21), and inhibit the proliferation and metastasis of colorectal cancer HT29 cells $(22,23)$ and high glucoseinduced retinal vascular endothelial cells(24). In addition, our previous study found that Scutellaria barbata polysaccharide (SBPs) inhibit tumor growth in hepatoma H22-bearing mice(25). However, most of the studies on SBPs involved the crude polysaccharides, and the isolation, purification and antihepatoma activity of SBPs have not been studied. Furthermore, the unique antitumor properties of SBPs limit their potential for clinical application due to the lack of clear structural and mechanistic information.

Based on the above considerations, this study was designed to obtain the crude polysaccharide of Scutellaria barbata by using water extraction and alcohol precipitation, optimize the extraction process with response surface methodology and purify the crude SBP by column chromatography to obtain SBP$1 \mathrm{~A}$ and SBP-2A. The polysaccharide content, molecular weight, monosaccharide composition and basic structure were preliminarily identified. Then, a MTT assay was used to identify the polysaccharide components with anti-hepatoma effects. The antitumor activity of SBP-2A was evaluated by colony formation tests, morphological observations, apoptosis and cell cycle analyses.

\section{Materials And Methods}

2.1. Materials: Scutellaria barbata was purchased from Hebei Jinyezi Pharmaceutical Co., Ltd. (Hebei, China); the finely sieved powder was kept in a constant weight dryer until it was dry. The fine powder was crushed through a 40 mesh sieve and stored in a dryer until use. DEAE-52 cellulose was purchased from Phygene Biotechnology Co., Ltd. (Fuzhou, China), and Sephadex G-100 was purchased from GE Healthcare Bio-Sciences AB (Uppsala, Sweden). Monosaccharide standards were provided by Shenzhen Bo Rui Sugar Biology Co., Ltd. (Shenzhen, China). All other reagents used in the tests were analytical

grade and obtained from local chemical suppliers in China. The human hepatoma HepG2 cell line was 
purchased from the Chinese Academy of Sciences (Shanghai, China). MEM dry powder, penicillin and streptomycin, trypsin, non-essential amino acids (NEAA) and sodium pyruvate in $100 \mu \mathrm{g} / \mathrm{ml}$ penicillin and $100 \mu \mathrm{g} / \mathrm{ml}$ streptomycin were purchased from Gibco Inc. (Gibco, USA). Australian fetal bovine serum (FBS) was purchased from Wuxi Xinrun Biotechnology Co., Ltd. (Wuxi, Jiangsu). 3-(4,5-Dimethylthiazol-2yl)-2,5-diphenyltetrazolium bromide (MTT) cell proliferation and cytotoxicity test kits and DNA content test kits were purchased from Solebao (Beijing, China). A Hoechst 33258 apoptosis staining kit was purchased from Beyotime Co., Ltd. (Nanjing, China).

\subsection{Optimization of water extraction and alcohol precipitation with response surface methodology}

\subsubsection{Single factor experimental design}

Chunlin Ye optimized the extraction parameters for Scutellaria barbata with response surface methodology, and the polysaccharide yield was only $2.43 \pm 0.11 \%(26)$. To further improve the polysaccharide yield based on the process for extraction of crude Scutellaria barbata polysaccharide, we selected three factors: liquid-material ratio, extraction temperature and extraction time. Five levels were investigated for each factor(27, 28), including: liquid-material ratios; $1: 10,1: 15,1: 20,1: 25$ and 1:30; extraction temperatures: $60^{\circ} \mathrm{C}, 70^{\circ} \mathrm{C}, 80^{\circ} \mathrm{C}, 90^{\circ} \mathrm{C}$ and $100^{\circ} \mathrm{C}$; and extraction times: $1 \mathrm{~h}, 2 \mathrm{~h}, 3 \mathrm{~h}, 4 \mathrm{~h}$ and $5 \mathrm{~h}$. The content of SBP was determined.

\subsubsection{Response surface methodology}

According to the results of the single-factor experiments, three factors and five levels of box Behnken experimental design were carried out to optimize the extraction conditions, and the related experiments were generated by Design Expert 11 (State-Ease Inc., Minneapolis, MN, USA) RSM software and repeated three times for each group. RSM was used for regression analyses of the experimental data, and a nonlinear quadratic model was fitted according to the formula $(29,30)$.

\subsection{Extraction of Scutellaria barbata crude polysaccharide (SBP) by water extraction and alcohol precipitation}

Scutellaria barbata powder was soaked in $95 \%$ ethanol solution several times to decolorize the powder and remove alcohol-soluble components. The filter residue was dried for $24 \mathrm{~h}$ to prepare the Scutellaria barbata sample. With a ratio for material to liquid of $1: 25(\mathrm{~g} / \mathrm{ml}), 90^{\circ} \mathrm{C}$ hot water extraction was used for two extractions lasting $2 \mathrm{~h}$ each time, the mixture was centrifuged for $15 \mathrm{~min}$ at $3500 \mathrm{rpm} / \mathrm{min}$, the supernatant was combined, rotated and evaporated at $55^{\circ} \mathrm{C}$ and concentrated to $1 / 4$ of the original volume; 4 volumes of absolute ethanol were added slowly to the concentrated solution with stirring, and the solution was cooled to $4{ }^{\circ} \mathrm{C}$. The precipitate was collected, diluted with water and deproteinized (volume ratio 1:5) with Savage reagent (the chloroform:n-butanol volume ratio was 4:1)(31, 32). The solution was decolorized with macroporous resin D101 and filtered, and the extract was separated and concentrated to $1 / 4$ of the original volume under reduced pressure at $55^{\circ} \mathrm{C}$. SBP was prepared by vacuum drying at $50^{\circ} \mathrm{C}$ and stored in a dryer until use. 


\subsection{SBP purification}

DEAE-52 cellulose was loaded onto an ion chromatography column $(2.5 \mathrm{~cm} \times 100 \mathrm{~cm})$ for purification of polysaccharides with an ultrapure water balance. Polysaccharide $(200 \mathrm{mg})$ was dissolved in $10 \mathrm{ml}$ of distilled water, injected into the balanced chromatographic column, eluted successively with distilled water, $0.1 \mathrm{M}, 0.2 \mathrm{M}, 0.3 \mathrm{M}, 0.5 \mathrm{M}$ and $1 \mathrm{M} \mathrm{NaCl}$ solution gradient. The flow rate was adjusted to $1 \mathrm{ml} / \mathrm{min}$, $10 \mathrm{ml} /$ tube of eluent was collected by the automatic collector, and the absorbance at $490 \mathrm{~nm}$ was measured with the phenol sulfuric acid method(33). The elution solutions were combined, rotated and concentrated to $1 / 8$ of the original volume at $55^{\circ} \mathrm{C}$; a dialysis bag with molecular weight of $3500 \mathrm{Da}$ was used for $24 \mathrm{~h}$ to collect the dialysate, which was prefrozen at $-40{ }^{\circ} \mathrm{C}$ for $24 \mathrm{~h}$, and then freeze-dried into powder(34). Samples were placed on a SephadexG-100 dextran gel column and washed with ultrapure water at $5 \mathrm{ml} /$ tube. The polysaccharide content of each tube was measured by the phenol sulfuric acid method, and elution curves were drawn. If the component showed a single symmetrical elution peak after the SephadexG-100 gel column, it contained a single polysaccharide component. The main peak components were concentrated, frozen and dried to obtain white flocculated polysaccharides.

\subsection{Polysaccharide and protein content}

A glucose standard solution, $0.1 \mathrm{mg} / \mathrm{ml}$, was prepared and $0,0.4,0.6,0.8,1.0,1.2,1.4,1.6$, and $1.8 \mathrm{ml}$ of glucose standard solution was added into stoppered test tubes. Distilled water was added to establish a volume of $2 \mathrm{ml}, 1 \mathrm{ml}$ of $5 \%$ phenol was added and mixed well, and $5 \mathrm{ml}$ of concentrated sulfuric acid was added quickly. The mixture was warmed in a $40{ }^{\circ} \mathrm{C}$ water bath for $30 \mathrm{~min}$ and allowed to stand for 20 min, after cooling to room temperature, the absorbance value at $490 \mathrm{~nm}$ was measured with an ultraviolet spectrophotometer; the glucose standard concentration $(\mu \mathrm{g} / \mathrm{ml})$ was the abscissa, and the absorbance value $A$ was the ordinate used to draw the glucose standard curve. One milligram of SBP was weighed and fully dissolved in distilled water. The absorbance value was determined at $490 \mathrm{~nm}$ according to the phenol sulfuric acid method(33), and the polysaccharide concentration in the sample was calculated according to the standard curve. Then, according to the number of standards and samples, a BCA working solution was prepared to give a 50:1 ratio of BCA reagent and Cu reagent. A $10 \mu \mathrm{l}$ sample of BSA standard was diluted to $100 \mu \mathrm{l}(0.5 \mathrm{mg} / \mathrm{ml})$ with PBS. The standard $(0,2,4,6,8,12,16,20 \mu \mathrm{l})$ was added to 96 well plates, and PBS was added to increase the volumes to $20 \mu \mathrm{l}$. The sample was weighed and diluted with PBS, and $20 \mu \mathrm{l}$ was added to a 96 well plate with $200 \mu \mathrm{l} /$ well BCA working solution; the plate was warmed at $37^{\circ} \mathrm{C}$ for $15-30 \mathrm{~min}$. The absorbance value at $562 \mathrm{~nm}$ was measured by enzyme labeling instrument (Multiskan MK3, ThermoFisher, USA), and the protein concentration was calculated according to the standard curve.

\subsection{Monosaccharide composition}

Sixteen monosaccharide standards were prepared as $10 \mathrm{mg} / \mathrm{ml}$ standard solutions. The $0.01,0.1,0.5,1$, 5,10 and $20 \mathrm{mg} / \mathrm{L}$ gradient concentration standards of monosaccharide standard solutions were labelled as standards 1-7. Ten milligrams of sample was accurately weighed and placed into an ampoule bottle, $10 \mathrm{ml}$ of $3 \mathrm{M}$ TFA was added and the substrate was hydrolyzed at $120^{\circ} \mathrm{C}$ for $3 \mathrm{~h}$. The acid hydrolysis 
solution was absorbed, transferred into the tube, blown dry with nitrogen, added to $5 \mathrm{ml}$ of water, vortexed and mixed evenly, diluted to $100 \mu \mathrm{l}$, added to $900 \mu \mathrm{l}$ of deionized water, and centrifuged at 12,000 rpm for $5 \mathrm{~min}$. The supernatant was removed for ion chromatography (IC) analysis(35) with an ICS5000 system (Thermo Fisher, USA).

\subsection{Molecular weight determination}

High-performance liquid chromatography (HPLC) is widely used in determinations of molecular weight because of its high accuracy and efficiency(36). Samples and standards were weighed accurately (molecular weights were 5000, 11600, 2800, 48600, 80900, 148000, 273000, 409800, 667800 and $3693000 \mathrm{Da}$, respectively), $5 \mathrm{mg} / \mathrm{ml}$ solutions were prepared, the solutions were centrifuged at $12000 \mathrm{rpm}$ for $10 \mathrm{~min}$ and the supernatant was filtered through $0.22 \mu \mathrm{m}$ microporous filters, and the sample was transferred into a $1.8 \mathrm{ml}$ injection vial. The chromatographic conditions for HPLC (LC10A, Shimadzu, Japan) were as follows: chromatographic column: BRT105-104-102 tandem gel column $(8 \times 300 \mathrm{~mm})$; mobile phase: $0.05 \mathrm{NaCl}$ solution; flow rate: $0.6 \mathrm{ml} / \mathrm{min}$, column temperature: $40^{\circ} \mathrm{C}$; injection volume: $20 \mu$ l; detector: differential refractive index detector RID-10A. By taking the logarithm of the molecular weight of the standard $(\log (\mathrm{Mw}))$ as the ordinate and the peak time $(\mathrm{min})$ as the abscissa, regression fitting of the curve was performed with software to obtain the standard curve for molecular

weight distribution. The chromatogram of the sample was obtained with the chromatographic separation conditions described above, the retention time of a single symmetrical peak was recorded, and the molecular weight was calculated.

\subsection{FT-IR analysis}

Samples were analyzed by Fourier transform infrared (FT-IR) spectroscopy(37) in a pressed $\mathrm{KBr}$ pellet. Polysaccharide ( $5 \mathrm{mg}$ ) was weighed, put into a mortar with dried $\mathrm{KBr}$, mixed and ground fully, pressed into a thin sheet with a pellet press, and analyzed with a Thermo Scientific Nicolet iS5 FT-IR spectrophotometer (Thermo Nicolet Co., Madison, WI, USA) with a scan range of $500-4000 \mathrm{~cm}^{-1}$.

\subsection{Anti-hepatoma activity}

\subsubsection{MTT assay}

The MTT assay was used to screen the SBP component with the highest antitumor activity. HepG2 cells were inoculated in a 96 well microplate, warmed in an incubator to $37{ }^{\circ} \mathrm{C}$ under $5 \% \mathrm{CO}_{2}$ to adhere to the wall, and cultured with different concentrations $(50-3200 \mu \mathrm{g} / \mathrm{ml})$ of SBP, SBP-1A and SBP-2A for $48 \mathrm{~h}$. Then $20 \mu \mathrm{l} /$ well of MTT solution $(5 \mathrm{mg} / \mathrm{ml})$ was added, the mixture was cultured for $4 \mathrm{~h}$, the liquid was discarded and $150 \mu \mathrm{l} /$ well of DMSO was added. The system was oscillated at low speed for $10 \mathrm{~min}$, and the absorbance (OD) value at $490 \mathrm{~nm}$ was measured with a SpectraMax M3 microplate reader (Molecular Devices, USA). $A_{1}$ represents the OD value of the experimental group, and $A_{2}$ represents the OD value of the negative control group. 
Inhibition rate $(\%)=\left(1-A_{1} / A_{2}\right) \times 100 \%$

The $\mathrm{IC}_{50}$ values of three polysaccharides with different concentrations were calculated by GraphPad Prism software. According to the $\mathrm{IC}_{50}$ value, low, medium and high doses of SBP-2A were determined for studying the anti-hepatoma effect.

\subsubsection{Colony forming assay}

HepG2 cells were added at 4000 cells/well and inoculated in $35 \mathrm{~mm}$ dishes, adherent HepG2 cells were treated with SBP-2A for $48 \mathrm{~h}$. The same amount of MEM complete medium was added to each dish for routine culturing for 10 days. The culture medium was discarded and the cells were washed with PBS and fixed with $4 \%$ paraformaldehyde for $30 \mathrm{~min}$. The paraformaldehyde was discarded and the cells were washed twice with PBS, dyed with $0.1 \%$ crystal violet for 20 min, cleaned with PBS buffer and photographed, and the number of colonies with more than 50 cells were counted. The colony forming ability of HepG2 cells treated with different concentrations of SBP-2A was detected by a cell colony forming assay.

Clone formation rate $(\%)=$ number of cell clones/number of inoculated cells .

\subsubsection{Cell morphology observation}

HepG2 cells in the logarithmic growth stage were cocultured with SBP-2A for $48 \mathrm{~h}$. The morphological changes in HepG2 cells were directly observed with a DMI 6000B Leica microsystem (Wetzlar, Germany). Then, the culture medium was absorbed, $0.5 \mathrm{ml}$ of fixing solution was added, and the cells were fixed for 20 min; the cells were washed with PBS, cultured with Hoechst 33258 staining solution for 10 min, and rinsed with PBS. After blocking with an anti-fluorescence quencher, morphological changes due to apoptosis of HepG2 cells induced by SBP-2A were observed under a DMI 6000B Leica microsystem.

\subsubsection{Annexin V-FITC/PI staining assay and cell cycle detection}

HepG2 cells were added at $5 \times 10^{5}$ cells/well and inoculated in $35 \mathrm{~mm}$ dishes, and the cells were treated with SBP-2A for $48 \mathrm{~h}$. The cells were digested, centrifuged (700 rpm, $4 \mathrm{~min}$ ), collected and washed twice with precooled PBS to obtain the cell precipitate, which was resuspended in $500 \mu$ of binding buffer. Then, $5 \mu \mathrm{l}$ Annexin V-FITC dye solution and $10 \mu \mathrm{l} \mathrm{PI}$ were added with mixing, and the reaction was kept in the dark at room temperature for $15 \mathrm{~min}$. Finally, apoptosis was evaluated by a Cytomics FC500 Flow Cytometry CXP system (Beckman, USA), and the percentage of apoptotic cells was analyzed by FlowJo v10.6.2. software.

The cell cycle distribution of the SBP-2A-treated HepG2 cell line was evaluated by flow cytometry. The cells were seeded at a density of $5 \times 10^{5}$ cells/well and inoculated in $35 \mathrm{~mm}$ cell culture dishes. After adding adherent, the cells were starved with MEM culture medium containing $1 \%$ FBS for $12 \mathrm{~h}$. The cells were treated with SBP-2A solutions for $48 \mathrm{~h}$. With a sample collection rate of $1 \times 10^{6}$ cells $/$ piece, cell 
precipitates were obtained by centrifugation, $300 \mu \mathrm{l}$ of precooled PBS was added to resuspend them, 700 $\mu \mathrm{l}$ of precooled absolute ethanol was slowly added drop by drop with mixing, and then the cells were fixed overnight at $-4{ }^{\circ} \mathrm{C}$. The fixing solution was washed away with PBS, and $100 \mu \mathrm{l}$ of RNase A solution was added to the cell precipitate to resuspend it. The mixture was warmed in a water bath at $37^{\circ} \mathrm{C}$ for $30 \mathrm{~min}$, $400 \mu \mathrm{l}$ of PI staining solution was added and mixed, and the cells were incubated in the dark at $4{ }^{\circ} \mathrm{C}$ for 30 min. Finally, the cell cycle of the sample was evaluated by Cytomics FC500 Flow Cytometry CXP (Beckman, USA) and the cycle results were analyzed by ModFit LT 5.0 software.

\subsection{Statistical analyses}

All data were expressed as the mean \pm standard deviation (SD). All experiments were repeated three times. One-way ANOVA and multiple comparisons were used, and all statistical analyses were performed using GraphPad Prism 7.0 software and plotted with Origin2021. $P<0.05$ was taken to indicate a statistically significant difference.

\section{Results}

\subsection{Single factor design of SBP extraction conditions}

Fig. 1 shows the effects of different extraction parameters on the efficiency for extraction of SBP. Fig. 1 (A) shows that the effects of the liquid-solid ratios 1:10, 1:15, 1:20, 1:25 and 1:30 on the extraction of SBP were investigated. The rates of polysaccharide extraction increased with increasing liquid-material ratio. When the liquid-material ratio was more than $1: 25$, the extraction rate increased rapidly, which may be because the increase in the liquid-to-material ratio allowed the polysaccharides to dissolve more fully $(38,39)$. Therefore, 1:25 was chosen as the center for the response surface experiment. As shown in Fig. 1(B), the effects of $60^{\circ} \mathrm{C}, 70^{\circ} \mathrm{C}, 80^{\circ} \mathrm{C}, 90^{\circ} \mathrm{C}$ and $100^{\circ} \mathrm{C}$ temperatures on the extraction of SBP were investigated. When the extraction temperature was $90^{\circ} \mathrm{C}$, the polysaccharide extraction rate reached the highest value. When the extraction temperature was varied between $60{ }^{\circ} \mathrm{C}$ and $90{ }^{\circ} \mathrm{C}$, the rate of polysaccharide extraction increased. With a further increase in temperature, the extraction rate showed a downward trend. Therefore, an extraction temperature of $90{ }^{\circ} \mathrm{C}$ was selected as the central point for the response surface experiment. As shown in Fig. 1(C), when the extraction times were $1 \mathrm{~h}$ and $2 \mathrm{~h}$, the rate of SBP extraction was higher, and prolonging the extraction time improved the yield of polysaccharide(40); the rate of SBP extraction decreased with extension of the time from $2 \mathrm{~h}$ to $4 \mathrm{~h}$, and it is possible that the structures of the polysaccharides changed during the long extraction process(41). Therefore, $2 \mathrm{~h}$ was selected as the center for the response surface experiment.

\subsection{Analysis of response surface optimization results}

\subsubsection{Regression model and analysis of variance}

According to the results of the single-factor experiment, a response surface optimization experiment with three factors and three levels was designed, with the rate of polysaccharide extraction as the response 
value and the liquid-solid ratio (A), extraction temperature (B) and extraction time (C) as the influencing factors. The experiment was designed with Design Expert 11 software. As shown in Table 1, a binary multiple equation relating the extraction rate of SBP $(y)$ and the three factors was obtained by data analysis:

$Y=3.91+0.045 A+0.125 B+0.113 C-0.068 A B+0.098 A C-0.118 B C-0.991 A^{2}-0.271 B^{2}+0.034 C^{2}$

$\mathrm{Y}$ is the extraction efficiency of SBP, $\mathrm{A}$ is the ratio of material to liquid, $\mathrm{B}$ is the extraction time, and $\mathrm{C}$ is the extraction temperature.

Significance tests were conducted for all models and regression model coefficients, and the results are shown in Table 2. The $\mathrm{F}$ value of the model was 143.86 , and $P<0.0001$, which indicates that the regression model was very significant; the model mismatch term $p$ value was $0.3838(P>0.05)$, so it was not significant at the level of $a=0.05$; this indicates that model fitting was effective and experimental error was small. The correlation coefficient $\mathrm{R}^{2}$ was 0.9946 , indicating that the simulated value of the model was consistent with the actual predicted value and the prediction of the model was reasonable; the coefficient of variation $(\mathrm{CV})$ was only $1.85 \%$, so the model exhibited good repeatability and high accuracy. From the $F$ values for the three influencing factors ( $A, B$ and $C$ ), it can be concluded that the effects of influencing factors on the extraction rate of SBP decreased in the order extraction time > extraction temperature > solid-liquid ratio.

\subsubsection{Response surface analysis and model optimization}

The response surface diagram and the contour map derived from the multiple quadratic regression model were used to evaluate the pairwise interactions of experimental factors and impacts on the extraction of SBP and determine the optimal level range for each factor. The steeper the slope of the response surface was, the higher the response sensitivity. The shape of the contour line reflects the strength of the interaction. The contour line for the solid-liquid ratio and the extraction time tended to be oval, indicating that the interactions were significant; the interactions of other factors were not significant (Fig. 2). The optimum extraction parameters for SBP were a solid-liquid ratio of 1:25.36, extraction time of $120.3 \mathrm{~min}$, and extraction temperature of $100{ }^{\circ} \mathrm{C}$.

\subsection{SBP purification}

Ion chromatography and gel column chromatography are usually used in the separation and purification of polysaccharides. The polysaccharide fractions with single peaks obtained by elution with $0.1 \mathrm{M}$ and $0.2 \mathrm{M} \mathrm{NaCl}$ solutions were the largest (Fig. 3). Therefore, the eluates with these two elution peaks were collected and named SBP-1 and SBP-2. The two components SBP-1 and SBP-2 were purified by a SephadexG-100 gel column. As shown in Fig. 4(A) and (B), the two components exhibited single and symmetrical elution peaks, demonstrating that the two polysaccharides were relatively homogeneous; the samples with the two single elution peaks were collected, freeze-dried into white flocculent powders, and named SBP-1A and SBP-2A. Five polysaccharide components were purified by ion column 
chromatography, but only polysaccharide components with high content, high purity and uniformity, namely, SBP-1A and SBP-2A, were retained due to limitations of the experimental conditions.

\subsection{Chemical composition analysis}

\subsubsection{Determination of polysaccharide content and protein content}

Analysis showed that the polysaccharide content of SBP-1A was $93.2 \%$ and that of SBP-2A was $95.5 \%$. A standard curve was obtained through determination of the BSA protein standard: $y=1.1702 x+0.1401, R^{2}$ $=0.9902$. The protein contents of the polysaccharide samples were determined: the protein content of SBP-1A was $2.87 \%$ and that of SBP-2A was $0.87 \%$ (Table 3 ).

\subsubsection{Monosaccharide composition}

The monosaccharide compositions of SBP-1A and SBP-2A were analyzed by ion chromatography. The peak sequences and retention times of the monosaccharide compositions were compared with those of chromatograms for the monosaccharide standard samples (Fig. 5). For the mixed standard, the peak at $2.0 \mathrm{~min}$ was for sodium hydroxide, and that at $40 \mathrm{~min}$ was the peak for sodium acetate. Table 3 shows the molar ratios of the monosaccharide samples. SBP-1A was mainly composed of arabinose $(30.6 \%)$ and galactose (38.4\%), and the uronic acid content was $0.7 \%$; SBP-2A was mainly composed of arabinose $(36.3 \%)$ and galactose $(42.7 \%)$, and the uronic acid content was $1.2 \%$. The monosaccharide constituents of the two components were fucose, galactosamine hydrochloride, rhamaose, arabinose, glucosamine hydrochloride, galactose, glucose, xylose and mannose, but the molar ratios were different. The molar ratio for SBP-1A was 0.6:0.3:0.6:30.6:3.3:38.4:16.1:8:1.4, and the molar ratio for SBP-2A was 0.6:0.5:0.8:36.3:4.4:42.7:9.2:3.6:0.7.

\subsubsection{Molecular weight determination}

The molecular weight distributions of SBP-1A and SBP-2A were determined by HPLC, and a standard curve equation was obtained: $\lg M w=-0.2078 x+12.968, R^{2}=0.993$. Fig. 6 shows a chromatogram with two polysaccharide components. Both SBP-1A and SBP-2A showed a symmetrical single peak, indicating that they are homogeneous acidic polysaccharides with high purity. The molecular weight of SBP-1A was $1.15 \times 10^{5} \mathrm{Da}$ (retention time: $38.051 \mathrm{~min}$ ), and the molecular weight of SBP-2A was $1.4 \times 10^{5} \mathrm{Da}$ (retention time: $37.642 \mathrm{~min}$ ).

\subsubsection{FT-IR Infrared spectroscopy}

As shown in Fig. 7, the infrared analysis showed that SBP-1A and SBP-2A had characteristic absorption peaks for polysaccharides near $3400 \mathrm{~cm}^{-1}$, and the strong absorption peak was the result of $\mathrm{O}-\mathrm{H}$ stretching vibrations in polysaccharides. The peak near $2900 \mathrm{~cm}^{-1}$ was assigned to $\mathrm{C}-\mathrm{H}$ stretching vibrations. There was a stretching vibration for $\mathrm{C}=0$ at $1634 \mathrm{~cm}^{-1}$, which may be due to a carboxyl or acetyl group, indicating the presence of uronic acid. The absorption peak near $1380 \mathrm{~cm}^{-1}$ was caused by 
the variable angle vibration of $\mathrm{C}-\mathrm{H}$, indicating that the polysaccharide had the $\beta$-characteristic absorption peak of dextran. A peak appeared near $1120 \mathrm{~cm}^{-1}$, indicating that the sugar residue of the polysaccharide was mainly pyranose.

\subsection{Anti-hepatoma activity of SBP-2A}

\subsubsection{SBP-2A inhibits HepG2 cell proliferation}

To identify the in vitro antitumor activities of isolated and purified SBP, the cell viability of hepatoma HepG2 cells treated with different concentrations of Scutellaria barbata polysaccharides (SBP, SBP-1A and SBP-2A) for $48 \mathrm{~h}$ was evaluated by the MTT method. Fig. 8 shows that growth inhibition for HepG2 cells increased with increasing SBP concentration. The average inhibition rates for SBP, SBP-1A and SBP$2 \mathrm{~A}$ increased from $17.29 \%$ to $66.35 \%, 2.13 \%$ to $70.19 \%$ and $18.02 \%$ to $76.53 \%$, respectively. Compared with SBP, SBP-1A and SBP-2A significantly inhibited the growth of HepG2 with doses ranging over 50-400 $\mu \mathrm{g} / \mathrm{ml}$, and their $\mathrm{IC}_{50}$ values were $891.7 \mu \mathrm{g} / \mathrm{ml}$ and $548.3 \mu \mathrm{g} / \mathrm{ml}$ after $48 \mathrm{~h}$. We found that when the concentration was $400 \mu \mathrm{g} / \mathrm{ml}$, the average inhibition rate for SBP-2A on HepG2 cells was $49.52 \%$, which was significantly higher than that of SBP-1A. Therefore, SBP-2A at concentrations of $200 \mu \mathrm{g} / \mathrm{ml}, 400$ $\mu \mathrm{g} / \mathrm{ml}$ and $800 \mu \mathrm{g} / \mathrm{ml}$ was preferred for subsequent anti-hepatoma experiments. Fig. 9(A, B) shows that the numbers of cell colonies formed by HepG2 cells treated with different concentrations of SBP-2A were decreased significantly compared with that of the control group. When the concentration was $800 \mu \mathrm{g} / \mathrm{ml}$, the number of colonies formed decreased most significantly, indicating that SBP-2A significantly inhibited colony formation by hepatoma cells; this was consistent with the results of the MTT assay.

\subsubsection{Morphological changes in apoptosis induced by SBP-2A}

As illustrated in Fig. 9(C), HepG2 cells with normal morphologies showed irregular spindle shapes, large numbers, full shapes and clustered adherent growth. Compared with the control group, HepG2 cells gradually lost their original normal cell morphology after treatment with increasing SBP-2A concentrations, which showed that the number of cells decreased significantly, the cells became flat and contracted into a lump, and cell membranes were broken; this resulted in unclear boundaries between cells and cell fragments. These results showed that SBP-2A significantly inhibited the proliferation of HepG2 cells in vitro.Fig. 9(D) shows that HepG2 cells showed typical apoptotic characteristics compared with the control group, such as dense nuclear staining and an increased bright blue density after $48 \mathrm{~h}$ of treatment with SBP-2A. However, with increasing SBP-2A concentration, the number of bright blue spots first increased and then decreased, preliminarily indicating that SBP-2A induced apoptosis of HepG2 cells.

\subsubsection{Effect of SBP-2A on the apoptosis rate and cycle distribution detected quantitatively by flow cytometry}

Fig. 10(A) shows that SBP-2A induced a significant level of early apoptosis for HepG2 cells compared with the untreated group. After treating cells with $200 \mu \mathrm{g} / \mathrm{ml}$ and $400 \mu \mathrm{g} / \mathrm{ml} \mathrm{SBP-2A}$, the early apoptosis 
rates increased significantly to $15.8 \%$ and $8.76 \%$, and the proportion of apoptosis induced by $200 \mu \mathrm{g} / \mathrm{ml}$ SBP-2A was more significant. As displayed in Fig. 10(B), by analyzing the percentage of DNA content in G1, S and $\mathrm{G} 2$ cells of the cell cycle, we found that, compared with the untreated group, increases in the SBP-2A concentration increased the percentage of cells in the G1 phase from $52.28 \%$ to $62.03 \%$, and the percentage of cells in the $\mathrm{G} 2$ phase was decreased from $34.22 \%$ to $26.97 \%$ in a dose-dependent manner.

\section{Discussions}

The common design methods for optimization of polysaccharide extraction include orthogonal tests and response surface optimization. In the optimization of the SBP extraction process, previous experiments were investigated by orthogonal testing. In this study, the response surface method was used for the first time to optimize the SBP extraction process. Compared with the orthogonal test, this method excluded random errors from the test and continuously analyzed all levels of the experiment in the optimization process to produce a continuous prediction model. In the single-factor experimental design, the efficiency for extraction of polysaccharide was lower at $100^{\circ} \mathrm{C}$ than at $90{ }^{\circ} \mathrm{C}$; this may be due to destruction of the polysaccharide structure when the temperature was too high, resulting in a decrease in the extraction rate(42-44). To facilitate practical operation, the process was improved as follows: the solid-liquid ratio was $1: 25$, the extraction time was $2 \mathrm{~h}$, and the extraction temperature was $90^{\circ} \mathrm{C}$. Under these conditions, three groups of repeated validation experiments were carried out, and the average extraction rate for SBP was $3.851 \pm 0.13 \%$, which was close to the predicted value of $4.06 \%$; this indicated that the model had good predictability and that the process optimized by the response surface method was reliable. Two polysaccharides (SBP-1A and SBP-2A) had been isolated from Scutellaria barbata and preliminary characterization of the SBP-1A and SBP-2A was investigated. Infrared spectroscopy is a method used for rapid analysis of polysaccharides, and it can accurately identify specific absorption peaks(45). The absorption peaks for SBP-1A and SBP-2A found between $4000-500 \mathrm{~cm}^{-1}$ were determined by infrared spectrometry using polysaccharide in a $\mathrm{KBr}$ pellet.

Many studies have shown that the low-toxicity natural polysaccharides extracted from Chinese herbal medicines inhibit the proliferation of tumor cells and selectively induce apoptosis(46). Different biological macromolecules can be obtained from different raw materials and extraction methods, and their types and structural characteristics affect the biological activities of polysaccharides(47-49). Studies have shown that long-term in vitro culturing or drug treatment of cells can inhibit cell colony formation $(50,51)$. Therefore, we further verified the effect of SBP-2A on the inhibition of HepG2 cell proliferation with colony formation assays. In vitro experiments preliminarily confirmed that SBP-2A inhibited the growth of HepG2 cells. We evaluated morphological changes in cells to better determine the induced apoptosis response to drugs(52-54). The morphological characteristics of HepG2 cells treated with SBP-2A for $48 \mathrm{~h}$ were directly observed by inverted microscopy. In this study, Hoechst 33258 staining was used to determine whether HepG2 cells could be induced to undergo apoptosis by SBP-2A. Cell cycle arrest and apoptosis are important processes in programmed cell death(55). To further evaluate the ability of SBP-2A to induce cell apoptosis and cycle arrest, HepG2 cells treated with SBP-2A for $48 \mathrm{~h}$ were stained by the annexin V- 
FITC/PI double staining method and the PI single staining method. The number of apoptotic cells and DNA content were measured quantitatively at each stage of the cell cycle by flow cytometry. In addition, the growth of normal and tumor cells was orderly in different stages of the cell cycle(56), which can induce cell cycle arrest and apoptosis and effectively inhibit the growth of tumor cells. Therefore, these results suggest that SBP-2A induced apoptosis of HepG2 cells and blocked apoptosis in the G1 phase of the cell cycle. The above experimental results showed that SBP-2A isolated and purified from Scutellaria barbata may be a candidate drug deserving further evaluation in cancer prevention, which provides

information for further studies on the molecular mechanism of its effect on human liver cancer cells. This could provide a basis for determining the effects of SBP against liver cancer and support its potential use as a functional medicinal component. Research on the anti-hepatoma mechanism of SBP-2A and its antitumor activity in $\mathrm{H} 22$ tumor-bearing mice is in progress.

\section{Conclusion}

In this study, the parameters for SBP extraction were optimized by the response surface method, and two uniform acidic polysaccharides, SBP-1A and SBP-2A, were obtained by column chromatography. They were preliminarily characterized based on their polysaccharide contents, molecular weights, monosaccharide compositions, infrared spectra and other structural characteristics. The MTT assay showed that SBP-2A significantly inhibited the proliferation of HepG2 cells and gradually destroyed the original normal cell morphology. Hoechst 33258 staining and annexin V-FITC/PI double staining showed that SBP-2A induced apoptosis of HepG2 cells by blocking the G1 phase.

\section{Abbreviations}

Crude Polysaccharide of Scutellaria Barbata (SBP)

Non-Essential Amino Acids (NEAA)

Fetal Bovine Serum (FBS)

3-(4,5-Dimethylthiazol-2-yl)-2,5-diphenyltetrazolium bromide (MTT)

Fourier Transform Infrared (FT-IR)

Coefficient of Variation $(\mathrm{CV})$

High-Performance Liquid Chromatography (HPLC)

\section{Declarations}

\section{Consent to publish}

All authors reviewed the results and approved the final version of the manuscript. 
Availability of data and materials

The datas used during the current study are available from the corresponding author on reasonable request.

\section{Ethics approval and consent to participate}

Not applicable

\section{Competing interests}

The authors declare no competing financial interest.

\section{Acknowledgments}

Not applicable.

\section{Funding}

This research was funded by the basic scientific research business fee project of Heilongjiang Provincial Department of Education (2018-KYYWFMY-0010), the Heilongjiang scientific research project of traditional Chinese Medicine (ZHY18-1168, ZQG-056), the innovative scientific research project for Postgraduates of Mudanjiang Medical University (YJSCX-MY16), the Postdoctoral Scientific Research Startup Fund of Heilongjiang Province (LBH-Q15141).

\section{Authors' Contributions}

GS and XX conceived and supervised the study; Experiments designed by GS and LW; LW, XL, WS and SY completed the separation, purification and identification of Scutellaria barbata polysaccharide under the guidance of QL; The antitumor activity of Scutellaria barbata polysaccharide was studied by WS, YL, YF and LL; WS, ZJ, DL, BZ analysis data and picture layout; WS wrote the manuscript; WS, QL, LW, YY revised the manuscript.

\section{Corresponding author}

Correspondence to is Gaochen Song.

\section{References}

1. Global, regional, and national life expectancy, all-cause mortality, and cause-specific mortality for 249 causes of death, 1980-2015: a systematic analysis for the Global Burden of Disease Study 2015, Lancet, 388 (2016) 1459-1544.

2. A.G. Singal, P. Lampertico, P. Nahon, Epidemiology and surveillance for hepatocellular carcinoma: New trends, J Hepatol, 72 (2020) 250-261. 
3. P. Tabrizian, G. Jibara, B. Shrager, M. Schwartz, S. Roayaie, Recurrence of hepatocellular cancer after resection: patterns, treatments, and prognosis, Ann Surg, 261 (2015) 947-955.

4. R.S. Finn, M. Ikeda, A.X. Zhu, M.W. Sung, A.D. Baron, M. Kudo, T. Okusaka, M. Kobayashi, H. Kumada, S. Kaneko, M. Pracht, K. Mamontov, T. Meyer, T. Kubota, C.E. Dutcus, K. Saito, A.B. Siegel, L. Dubrovsky, K. Mody, J.M. Llovet, Phase Ib Study of Lenvatinib Plus Pembrolizumab in Patients With Unresectable Hepatocellular Carcinoma, J Clin Oncol, 38 (2020) 2960-2970.

5. Q.X. Gan, J. Wang, J. Hu, G.H. Lou, H.J. Xiong, C.Y. Peng, Q.W. Huang, Modulation of Apoptosis by Plant Polysaccharides for Exerting Anti-Cancer Effects: A Review, Front Pharmacol, 11 (2020) 792.

6. D. Wei, T. Chen, M. Yan, W. Zhao, F. Li, W. Cheng, L. Yuan, Synthesis, characterization, antioxidant activity and neuroprotective effects of selenium polysaccharide from Radix hedysari, Carbohydr Polym, 125 (2015) 161-168.

7. L. Zhao, Y. Wang, H.L. Shen, X.D. Shen, Y. Nie, Y. Wang, T. Han, M. Yin, Q.Y. Zhang, Structural characterization and radioprotection of bone marrow hematopoiesis of two novel polysaccharides from the root of Angelica sinensis (Oliv.) Diels, Fitoterapia, 83 (2012) 1712-1720.

8. Q. Yuan, Y. Yuan, Y. Zheng, R. Sheng, L. Liu, F. Xie, J. Tan, Anti-cerebral ischemia reperfusion injury of polysaccharides: A review of the mechanisms, Biomed Pharmacother, 137 (2021) 111303.

9. J. Qu, P. Huang, L. Zhang, Y. Qiu, H. Qi, A. Leng, D. Shang, Hepatoprotective effect of plant polysaccharides from natural resources: A review of the mechanisms and structure-activity relationship, Int J Biol Macromol, 161 (2020) 24-34.

10. P. Cao, S. Wu, T. Wu, Y. Deng, Q. Zhang, K. Wang, Y. Zhang, The important role of polysaccharides from a traditional Chinese medicine-Lung Cleansing and Detoxifying Decoction against the COVID19 pandemic, Carbohydr Polym, 240 (2020) 116346.

11. W.L. Zhang, L. Zhu, J.G. Jiang, Active ingredients from natural botanicals in the treatment of obesity, Obes Rev, 15 (2014) 957-967.

12. M. Xie, W. Tao, F. Wu, K. Wu, X. Huang, G. Ling, C. Zhao, Q. Lv, Q. Wang, X. Zhou, Y. Chen, Q. Yuan, Y. Chen, Anti-hypertensive and cardioprotective activities of traditional Chinese medicine-derived polysaccharides: A review, Int J Biol Macromol, 185 (2021) 917-934.

13. D. Wang, Y. Liu, W. Zhao, The Adjuvant Effects on Vaccine and the Immunomodulatory Mechanisms of Polysaccharides From Traditional Chinese Medicine, Front Mol Biosci, 8 (2021) 655570.

14. E.T. Yeon, J.W. Lee, C. Lee, Q. Jin, H. Jang, D. Lee, J.S. Ahn, J.T. Hong, Y. Kim, M.K. Lee, B.Y. Hwang, neo-Clerodane Diterpenoids from Scutellaria barbata and Their Inhibitory Effects on LPS-Induced Nitric Oxide Production, J Nat Prod, 78 (2015) 2292-2296.

15. Q. Chen, K. Rahman, S.J. Wang, S. Zhou, H. Zhang, Scutellaria barbata: A Review on Chemical Constituents, Pharmacological Activities and Clinical Applications, Curr Pharm Des, 26 (2020) 160175.

16. L. De Luca, S. Trino, I. Laurenzana, D. Tagliaferri, G. Falco, V. Grieco, G. Bianchino, F. Nozza, V. Campia, F. D'Alessio, F. La Rocca, A. Caivano, O. Villani, D. Cilloni, P. Musto, L. Del Vecchio, 
Knockdown of miR-128a induces Lin28a expression and reverts myeloid differentiation blockage in acute myeloid leukemia, Cell Death Dis, 8 (2017) e2849.

17. M. Sandbothe, R. Buurman, N. Reich, L. Greiwe, B. Vajen, E. Gürlevik, V. Schäffer, M. Eilers, F. Kühnel, A. Vaquero, T. Longerich, S. Roessler, P. Schirmacher, M.P. Manns, T. Illig, B. Schlegelberger, B. Skawran, The microRNA-449 family inhibits TGF- $\beta$-mediated liver cancer cell migration by targeting SOX4, J Hepatol, 66 (2017) 1012-1021.

18. Z.J. Dai, B.F. Wang, W.F. Lu, Z.D. Wang, X.B. Ma, W.L. Min, H.F. Kang, X.J. Wang, W.Y. Wu, Total flavonoids of Scutellaria barbata inhibit invasion of hepatocarcinoma via MMP/TIMP in vitro, Molecules, 18 (2013) 934-950.

19. Y. Wu, D.F. Chen, Anti-complementary effect of polysaccharide B3-PS1 in Herba Scutellariae Barbatae (Scutellaria barbata), Immunopharmacol Immunotoxicol, 31 (2009) 696-701.

20. X. Yang, Y. Yang, S. Tang, H. Tang, G. Yang, Q. Xu, J. Wu, Anti-tumor effect of polysaccharides from Scutellaria barbata D. Don on the 95-D xenograft model via inhibition of the C-met pathway, J Pharmacol Sci, 125 (2014) 255-263.

21. J. Yang, G. Yang, G. Hou, Q. Liu, W. Hu, P.U. Zhao, Y.I. He, Scutellaria barbata D. Don polysaccharides inhibit the growth of Calu-3 xenograft tumors via suppression of the HER2 pathway and angiogenesis, Oncol Lett, 9 (2015) 2721-2725.

22. P. Sun, D. Sun, X. Wang, Effects of Scutellaria barbata polysaccharide on the proliferation, apoptosis and EMT of human colon cancer HT29 Cells, Carbohydr Polym, 167 (2017) 90-96.

23. H. Li, J. Su, J. Jiang, Y. Li, Z. Gan, Y. Ding, Y. Li, J. Liu, S. Wang, Y. Ke, Characterization of polysaccharide from Scutellaria barbata and its antagonistic effect on the migration and invasion of HT-29 colorectal cancer cells induced by TGF- $\beta 1$, Int J Biol Macromol, 131 (2019) 886-895.

24. W. Li, H. Xiao, Scutellaria barbata D. Don Polysaccharides Inhibit High Glucose-Induced Proliferation and Angiogenesis of Retinal Vascular Endothelial Cells, Diabetes Metab Syndr Obes, 14 (2021) 24312440 .

25. L. Li, X. Xu, L. Wu, H. Zhu, Z. He, B. Zhang, Y. Chi, G. Song, Scutellaria barbata polysaccharides inhibit tumor growth and affect the serum proteomic profiling of hepatoma H22-bearing mice, Mol Med Rep, 19 (2019) 2254-2262.

26. C.L. Ye, Q. Huang, Extraction of polysaccharides from herbal Scutellaria barbata D. Don (Ban-ZhiLian) and their antioxidant activity, Carbohydr Polym, 89 (2012) 1131-1137.

27. Y. Qu, C. Li, C. Zhang, R. Zeng, C. Fu, Optimization of infrared-assisted extraction of Bletilla striata polysaccharides based on response surface methodology and their antioxidant activities, Carbohydr Polym, 148 (2016) 345-353.

28. Z.Y. Zhao, Q. Zhang, Y.F. Li, L.L. Dong, S.L. Liu, Optimization of ultrasound extraction of Alisma orientalis polysaccharides by response surface methodology and their antioxidant activities, Carbohydr Polym, 119 (2015) 101-109.

29. X. Jia, C. Ding, S. Yuan, Z. Zhang, Y. Chen, L. Du, M. Yuan, Extraction, purification and characterization of polysaccharides from Hawk tea, Carbohydr Polym, 99 (2014) 319-324. 
30. R. Wang, P. Chen, F. Jia, J. Tang, F. Ma, Optimization of polysaccharides from Panax japonicus C.A. Meyer by RSM and its anti-oxidant activity, Int J Biol Macromol, 50 (2012) 331-336.

31. Y.L. Yao, C. Shu, G. Feng, Q. Wang, Y.Y. Yan, Y. Yi, H.X. Wang, X.F. Zhang, L.M. Wang, Polysaccharides from Pyracantha fortuneana and its biological activity, Int J Biol Macromol, 150 (2020) 1162-1174.

32. Y.Y. Chen, Y.T. Xue, Optimization of microwave assisted extraction, chemical characterization and antitumor activities of polysaccharides from porphyra haitanensis, Carbohydr Polym, 206 (2019) 179-186.

33. M. Dubois, K. Gilles, J.K. Hamilton, P.A. Rebers, F. Smith, A colorimetric method for the determination of sugars, Nature, 168 (1951) 167.

34. C. Zhang, F. Zhao, R. Li, Y. Wu, S. Liu, Q. Liang, Purification, characterization, antioxidant and moisture-preserving activities of polysaccharides from Rosa rugosa petals, Int J Biol Macromol, 124 (2019) 938-945.

35. Y. Hui, H. Jun-Li, W. Chuang, Anti-oxidation and anti-aging activity of polysaccharide from Malus micromalus Makino fruit wine, Int J Biol Macromol, 121 (2019) 1203-1212.

36. K. Li, L.J. Cui, Y.X. Cao, S.Y. Li, L.X. Shi, X.M. Qin, Y.G. Du, UHPLC Q-Exactive MS-Based Serum Metabolomics to Explore the Effect Mechanisms of Immunological Activity of Astragalus Polysaccharides With Different Molecular Weights, Front Pharmacol, 11 (2020) 595692.

37. M. Chylińska, M. Szymańska-Chargot, A. Zdunek, FT-IR and FT-Raman characterization of noncellulosic polysaccharides fractions isolated from plant cell wall, Carbohydr Polym, 154 (2016) 4854.

38. H. Wu, M. Li, X. Yang, Q. Wei, L. Sun, J. Zhao, H. Shang, Extraction optimization, physicochemical properties and antioxidant and hypoglycemic activities of polysaccharides from roxburgh rose (Rosa roxburghii Tratt.) leaves, Int J Biol Macromol, 165 (2020) 517-529.

39. K. Bargougui, K. Athmouni, M. Chaieb, Optimization, characterization and hepatoprotective effect of polysaccharides isolated from Stipa parviflora Desf. against $\mathrm{CCI}(4)$ induced liver injury in rats using surface response methodology (RSM), Int J Biol Macromol, 132 (2019) 524-533.

40. K. Mkadmini Hammi, M. Hammami, C. Rihouey, D. Le Cerf, R. Ksouri, H. Majdoub, Optimization extraction of polysaccharide from Tunisian Zizyphus lotus fruit by response surface methodology: Composition and antioxidant activity, Food Chem, 212 (2016) 476-484.

41. T. Ma, X. Sun, C. Tian, J. Luo, C. Zheng, J. Zhan, Polysaccharide extraction from Sphallerocarpus gracilis roots by response surface methodology, Int J Biol Macromol, 88 (2016) 162-170.

42. F. Li, J. Gao, F. Xue, X. Yu, T. Shao, Extraction Optimization, Purification and Physicochemical Properties of Polysaccharides from Gynura medica, Molecules, 21 (2016) 397.

43. L. Cai, B. Chen, F. Yi, S. Zou, Optimization of extraction of polysaccharide from dandelion root by response surface methodology: Structural characterization and antioxidant activity, Int J Biol Macromol, 140 (2019) 907-919.

44. T.T. Zhang, C.L. Lu, J.G. Jiang, M. Wang, D.M. Wang, W. Zhu, Bioactivities and extraction optimization of crude polysaccharides from the fruits and leaves of Rubus chingii Hu, Carbohydr Polym, 130 
(2015) 307-315.

45. S. Vogt, K. Löffler, A.G. Dinkelacker, B. Bader, I.B. Autenrieth, S. Peter, J. Liese, Fourier-Transform Infrared (FTIR) Spectroscopy for Typing of Clinical Enterobacter cloacae Complex Isolates, Front Microbiol, 10 (2019) 2582.

46. D. Sohretoglu, C. Zhang, J. Luo, S. Huang, ReishiMax inhibits mTORC1/2 by activating AMPK and inhibiting IGFR/PI3K/Rheb in tumor cells, Signal Transduct Target Ther, 4 (2019) 21.

47. H. Liu, X.Y. Sun, F.X. Wang, J.M. Ouyang, Regulation on Calcium Oxalate Crystallization and Protection on HK-2 Cells of Tea Polysaccharides with Different Molecular Weights, Oxid Med Cell Longev, 2020 (2020) 5057123.

48. J.Y. Chen, X.Y. Sun, J.M. Ouyang, Modulation of Calcium Oxalate Crystal Growth and Protection from Oxidatively Damaged Renal Epithelial Cells of Corn Silk Polysaccharides with Different Molecular Weights, Oxid Med Cell Longev, 2020 (2020) 6982948.

49. X. Zhao, J. Li, Y. Liu, D. Wu, P. Cai, Y. Pan, Structural characterization and immunomodulatory activity of a water soluble polysaccharide isolated from Botrychium ternatum, Carbohydr Polym, 171 (2017) 136-142.

50. H. Chen, X. Huang, C. Fu, X. Wu, Y. Peng, X. Lin, Y. Wang, Recombinant Klotho Protects Human Periodontal Ligament Stem Cells by Regulating Mitochondrial Function and the Antioxidant System during H(2)O(2)-Induced Oxidative Stress, Oxid Med Cell Longev, 2019 (2019) 9261565.

51. H. Lee, Y. Jang, S. Park, H. Jang, E.J. Park, H.J. Kim, H. Kim, Development and evaluation of a CEACAM6-targeting theranostic nanomedicine for photoacoustic-based diagnosis and chemotherapy of metastatic cancer, Theranostics, 8 (2018) 4247-4261.

52. Y. Zhang, J. Soto, K. Park, G. Viswanath, S. Kuwada, E.D. Abel, L. Wang, Nuclear receptor SHP, a death receptor that targets mitochondria, induces apoptosis and inhibits tumor growth, Mol Cell Biol, 30 (2010) 1341-1356.

53. M. Drefs, M.N. Thomas, M. Guba, M.K. Angele, J. Werner, M. Conrad, C.J. Steib, L.M. Holdt, J. Andrassy, A. Khandoga, M. Rentsch, Modulation of Glutathione Hemostasis by Inhibition of 12/15Lipoxygenase Prevents ROS-Mediated Cell Death after Hepatic Ischemia and Reperfusion, Oxid Med Cell Longev, 2017 (2017) 8325754.

54. W. Zhang, Z. Lei, J. Meng, G. Li, Y. Zhang, J. He, W. Yan, Water Extract of Sporoderm-Broken Spores of Ganoderma lucidum Induces Osteosarcoma Apoptosis and Restricts Autophagic Flux, Onco Targets Ther, 12 (2019) 11651-11665.

55. F. Zhang, J.J. Shi, K. Thakur, F. Hu, J.G. Zhang, Z.J. Wei, Anti-Cancerous Potential of Polysaccharide Fractions Extracted from Peony Seed Dreg on Various Human Cancer Cell Lines Via Cell Cycle Arrest and Apoptosis, Front Pharmacol, 8 (2017) 102.

56. F. Teloni, J. Michelena, A. Lezaja, S. Kilic, C. Ambrosi, S. Menon, J. Dobrovolna, R. Imhof, P. Janscak, T. Baubec, M. Altmeyer, Efficient Pre-mRNA Cleavage Prevents Replication-Stress-Associated Genome Instability, Mol Cell, 73 (2019) 670-683.e612. 
Figures
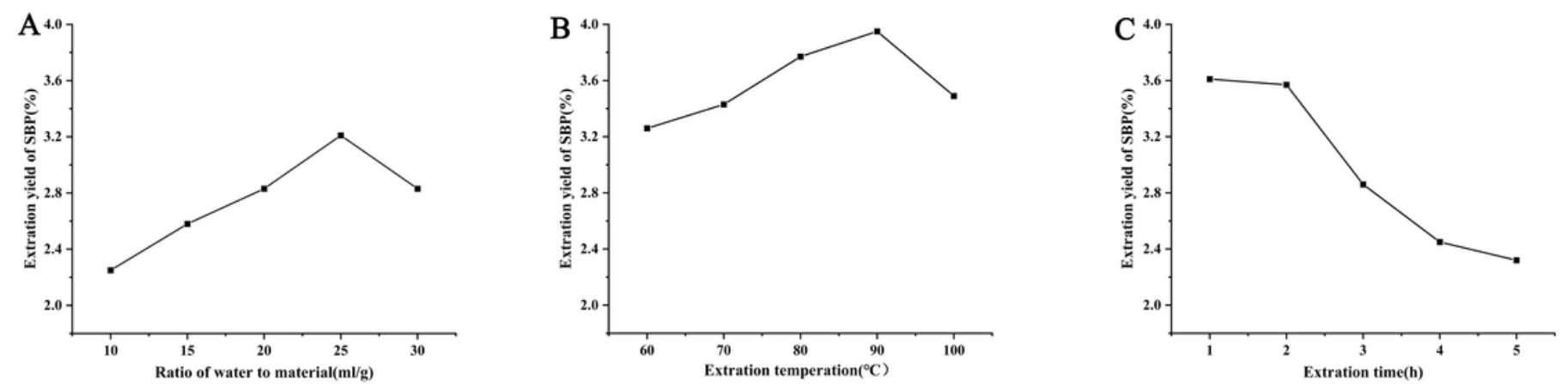

Figure 1

Effects of different liquid-solid ratios (A), extraction times (B) and extraction temperatures (C) on SBP extraction efficiency. 

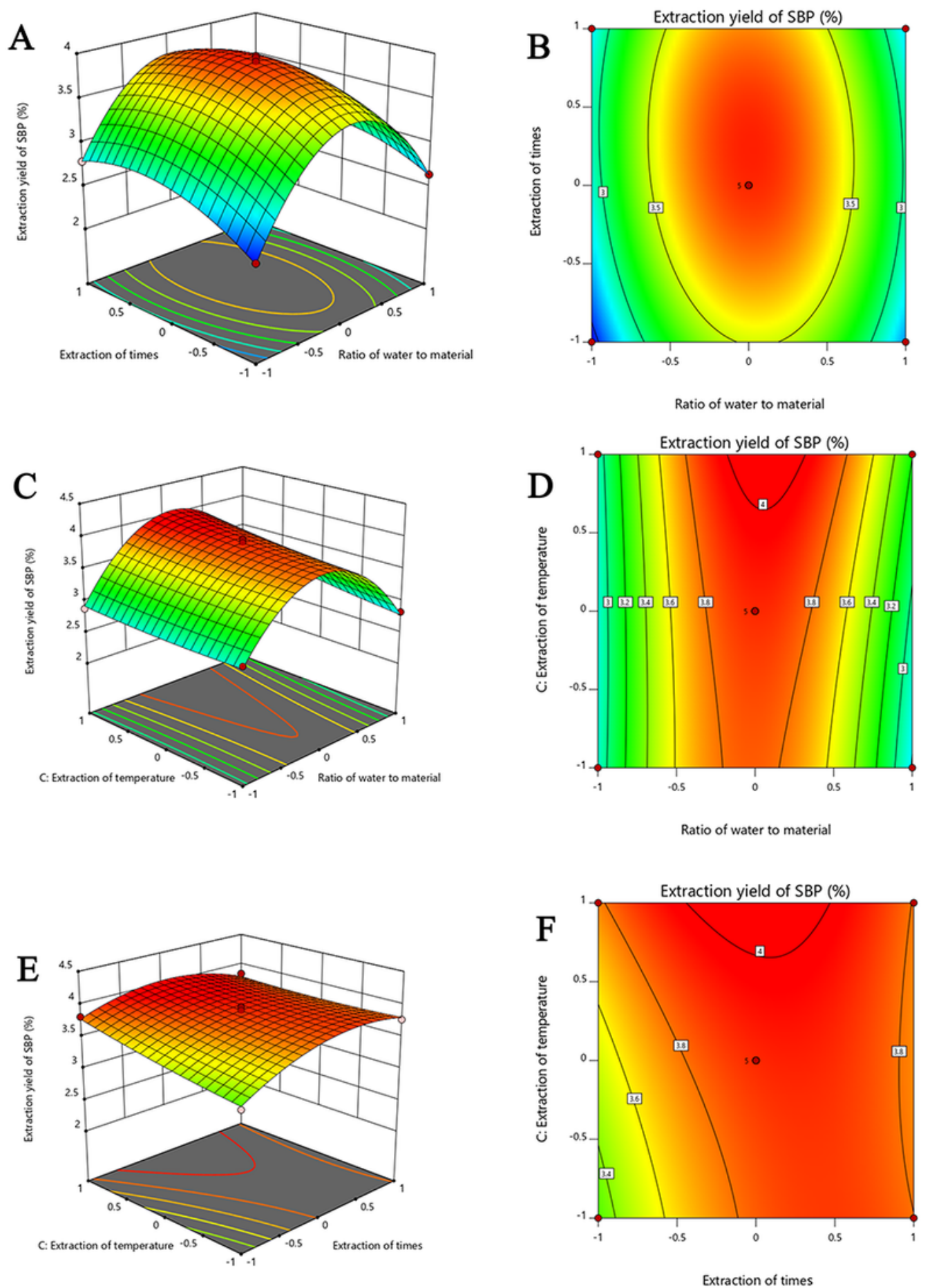

\section{Figure 2}

Response surface and contour map of the three-factor interaction in the SBP extraction rate. 


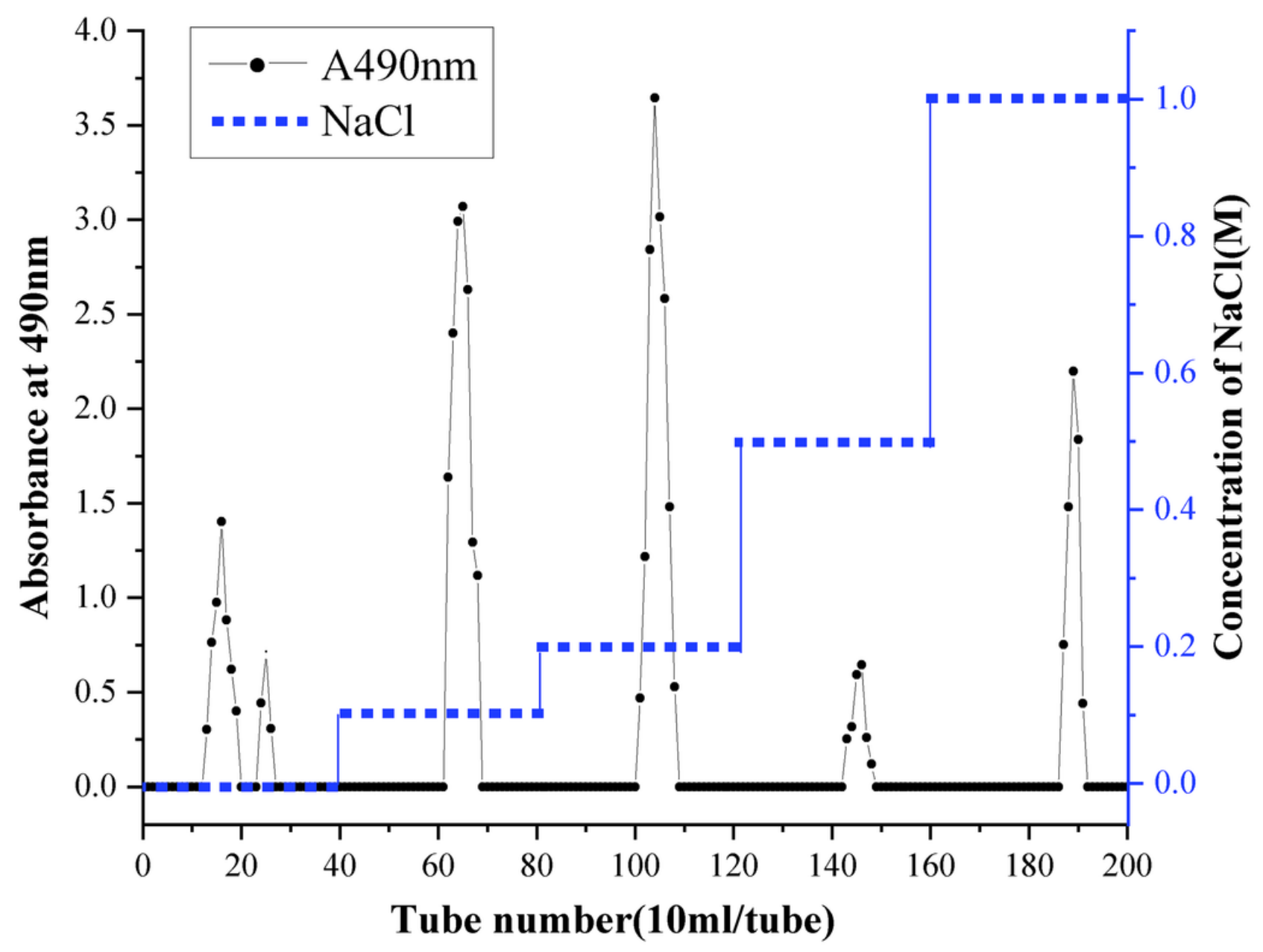

Figure 3

SBP was loaded on a DEAE-52 anion cellulose column and eluted successively with $\mathrm{NaCl}$ solutions $(0,0.1$ $\mathrm{M}, 0.2 \mathrm{M}, 0.5 \mathrm{M}$ and $1 \mathrm{M}$ ). The absorbance of the eluent at $490 \mathrm{~nm}$ was measured with a UV/visible spectrophotometer. 
A

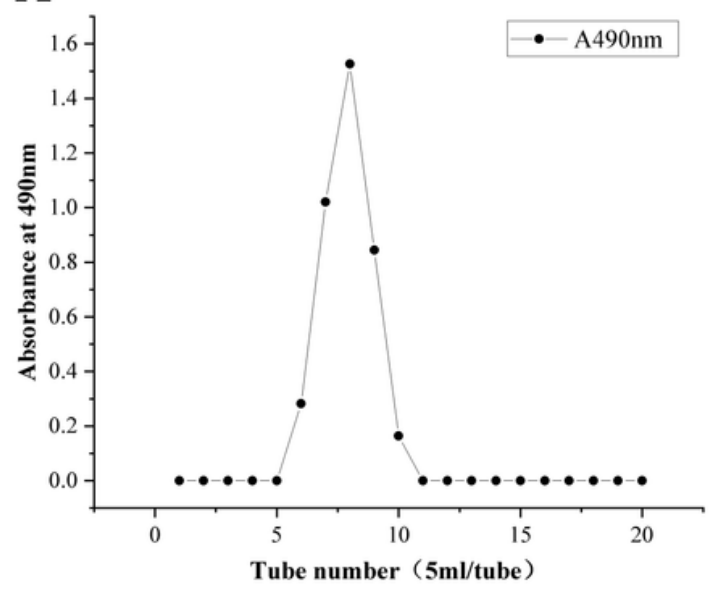

B

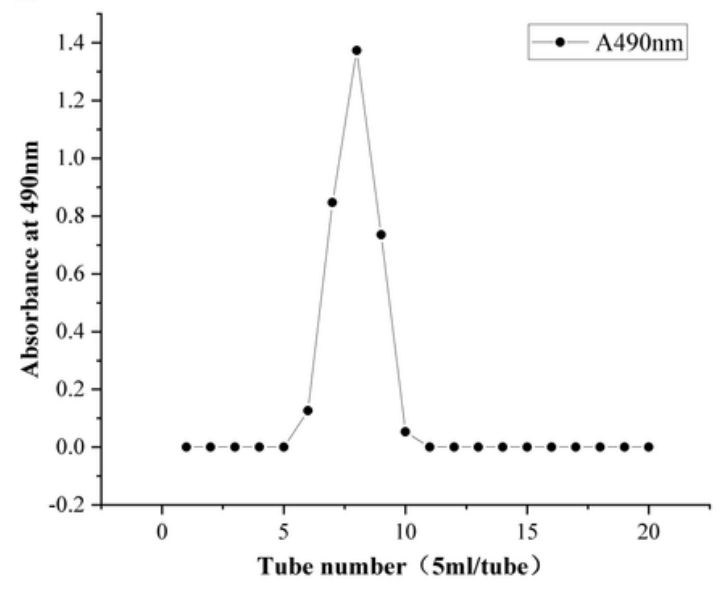

Figure 4

SBP-1A and SBP-2A were washed with deionized water and loaded on a Sephadex G-100 gel column. 


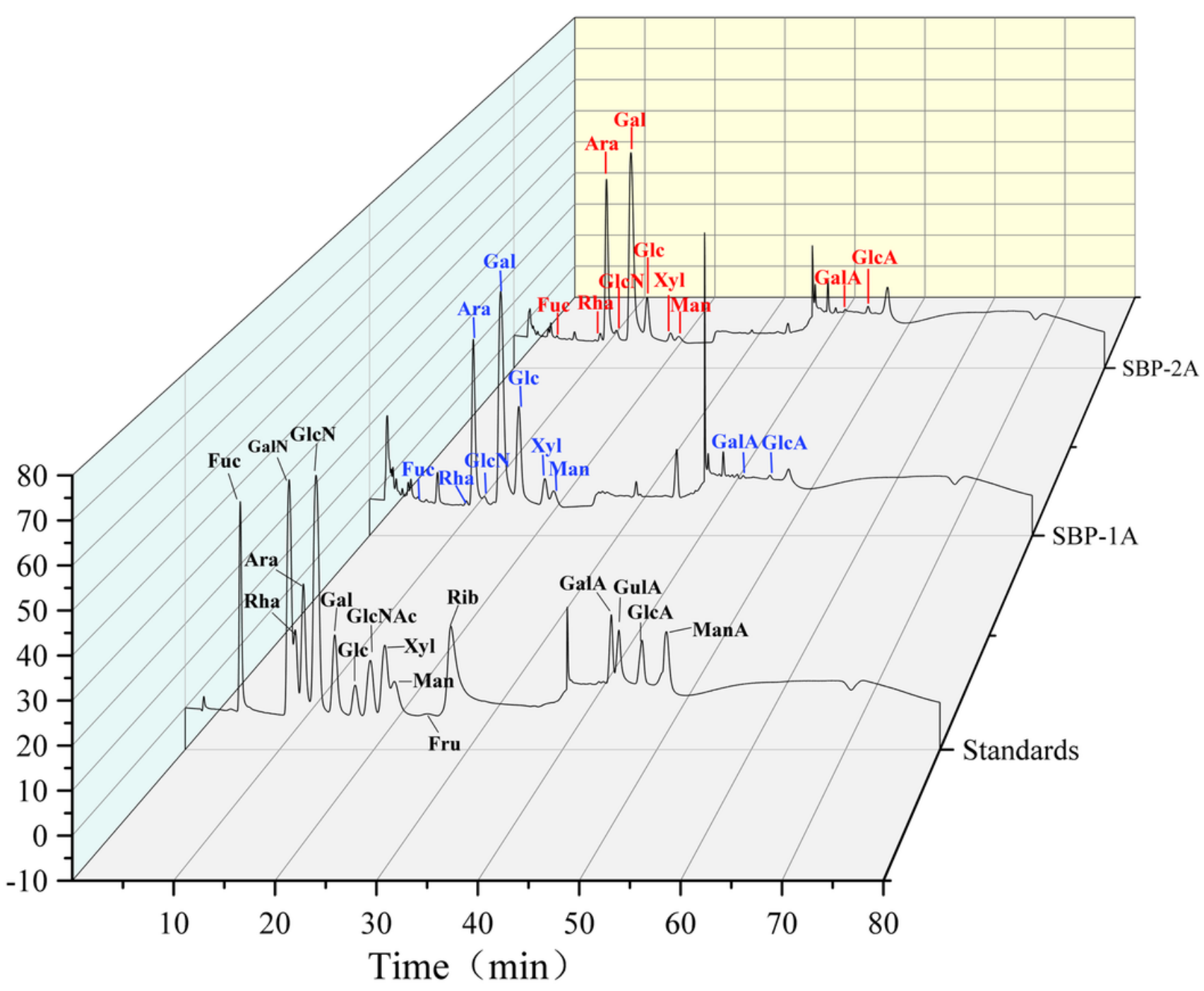

Figure 5

IC chromatogram of mixed monosaccharide standards SBP-1A and SBP-2A. 

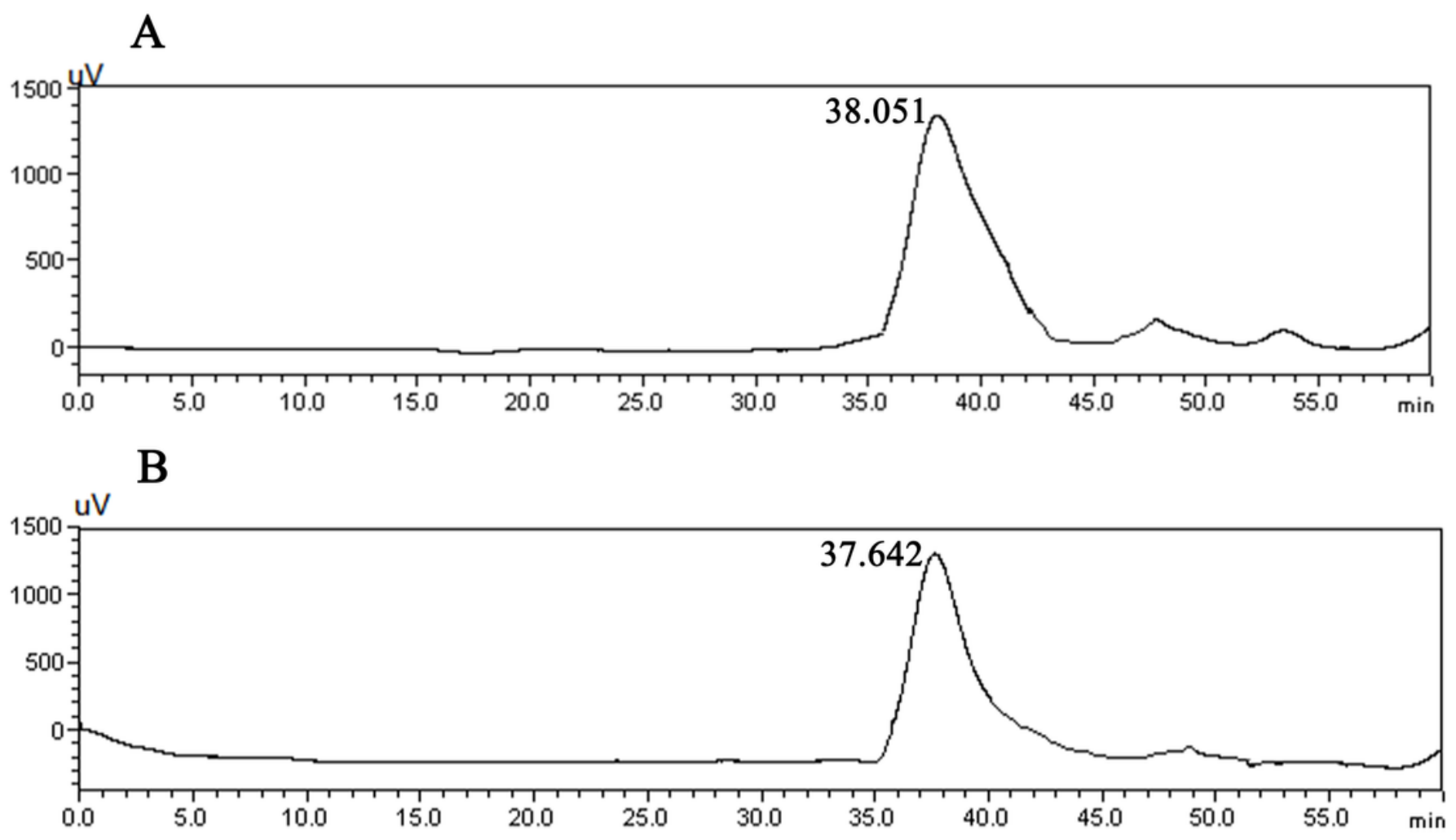

Figure 6

HPLC profiles of SBP-1A and SBP-2A. 

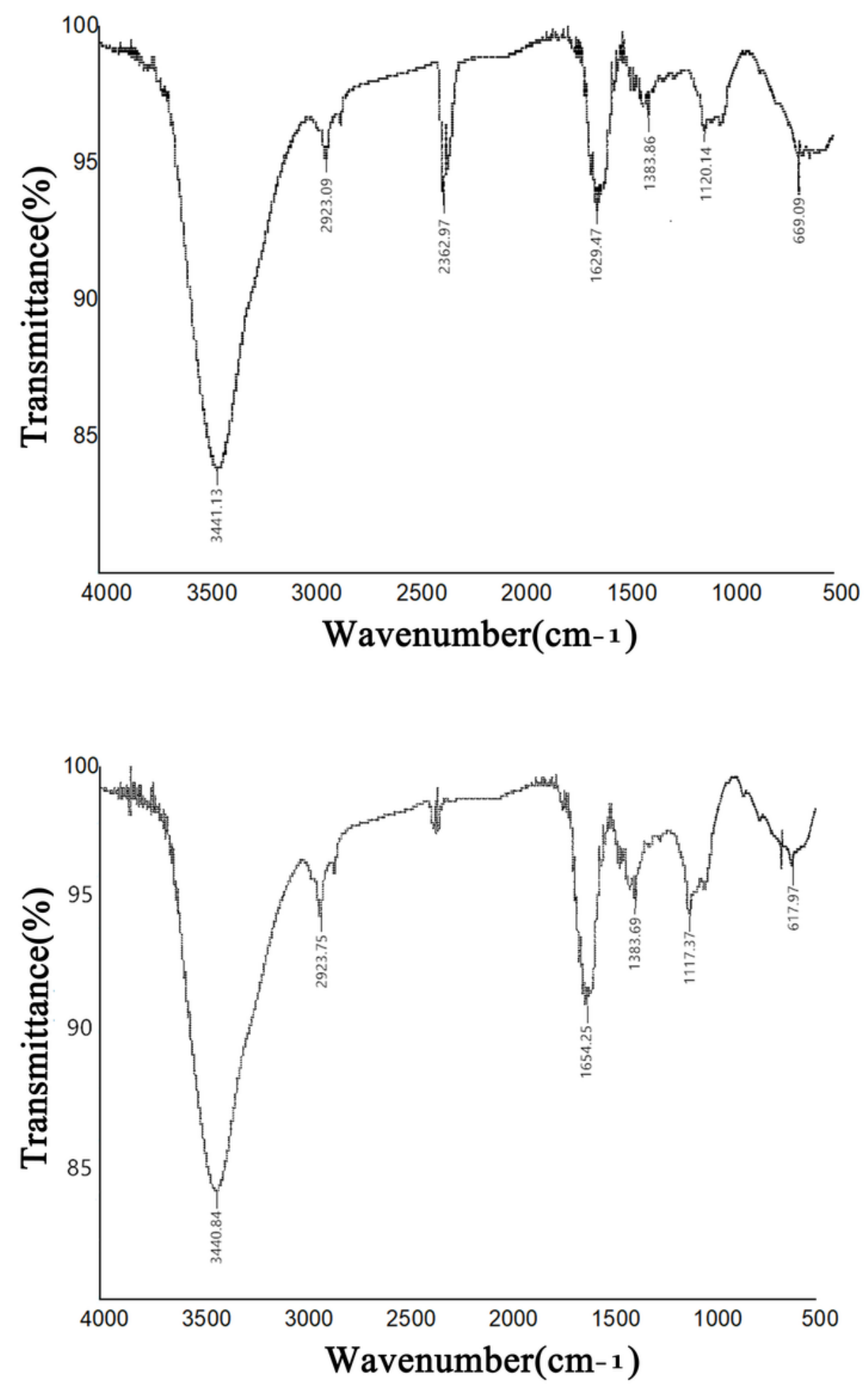

Figure 7

Absorption peaks for SBP-1A and SBP-2A were measured in $\mathrm{KBr}$ pellets by an infrared spectrometer with a spectral range of $4000-500 \mathrm{~cm}-1$.

展

Figure 8 
Proliferation inhibition levels for human hepatoma HepG2 cells treated with SBP, SBP-1A and SBP-2A for $48 \mathrm{~h}$ were measured by the MTT method.

A

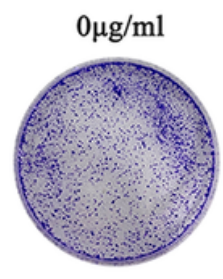

$0 \mu \mathrm{g} / \mathrm{ml}$
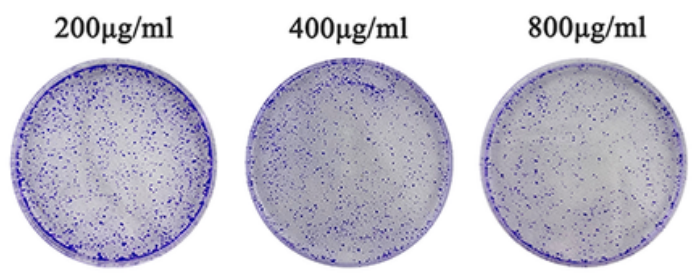

$200 \mu \mathrm{g} / \mathrm{ml}$

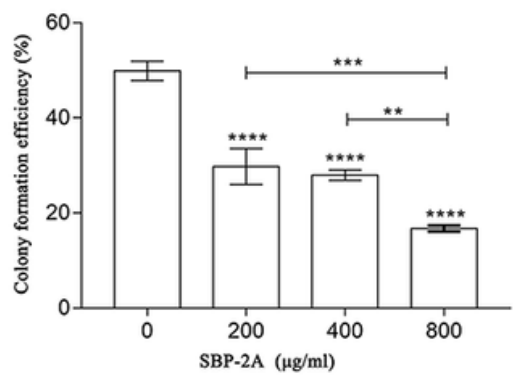

$400 \mu \mathrm{g} / \mathrm{ml}$

$800 \mu \mathrm{g} / \mathrm{ml}$

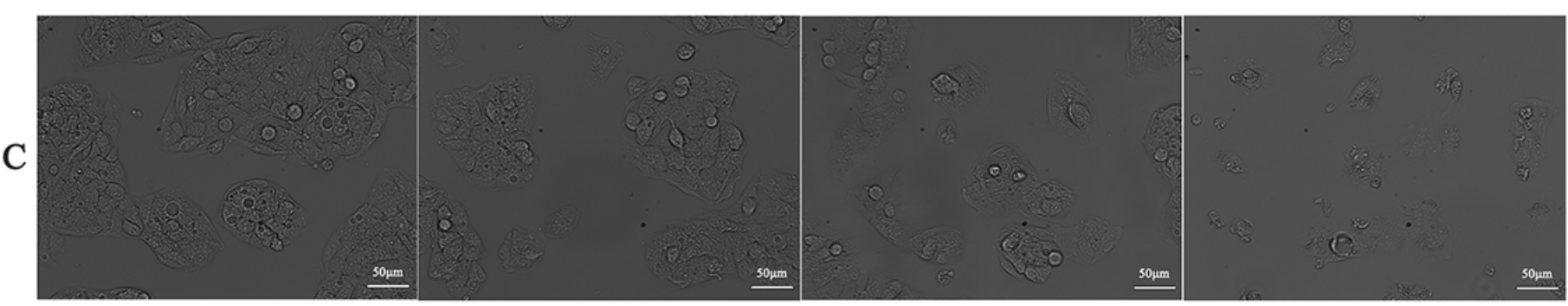

$\mathrm{D}$

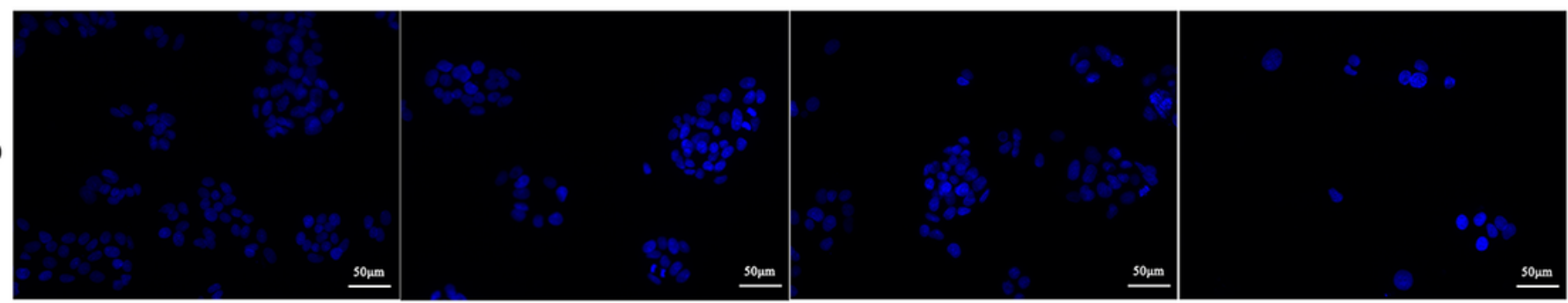

\section{Figure 9}

Colony formation assays further verified the effect of SBP-2A in inhibiting proliferation of HepG2 cells (A). The morphological characteristics of HepG2 cells treated with different concentrations of SBP-2A for $48 \mathrm{~h}$ were directly observed by inverted microscopy (B). Hoechst 33258 staining was used to detect the effects of SBP-2A on the apoptosis of HepG2 cells (C, D). 

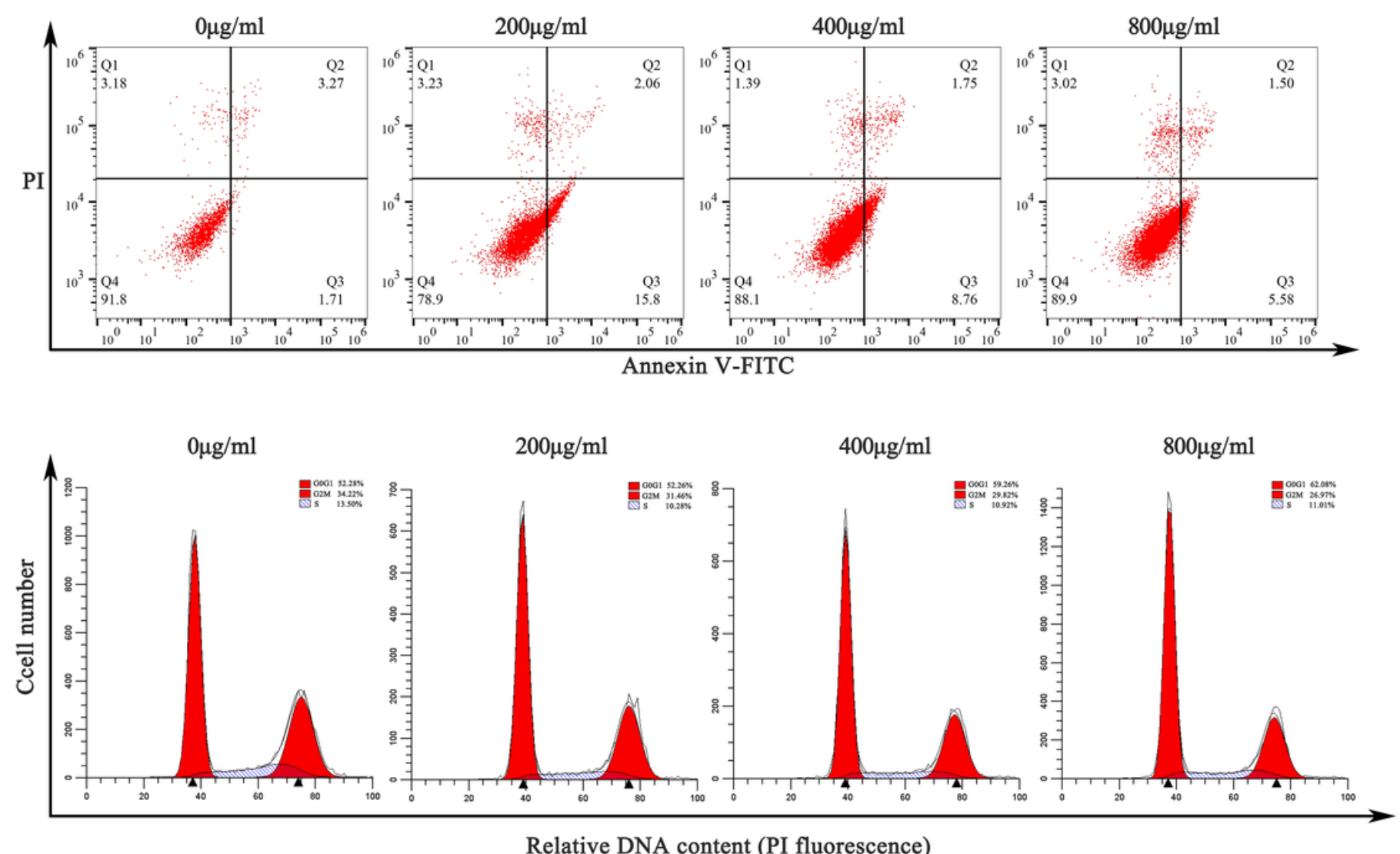

Figure 10

HepG2 cells treated with SBP-2A for $48 \mathrm{~h}$ were stained by the Annexin V-FITC/PI double staining method and the PI single staining method. The number of apoptotic cells (A) and DNA contents at each stage of the cell cycle (B) were measured quantitatively by flow cytometry.

\section{Supplementary Files}

This is a list of supplementary files associated with this preprint. Click to download.

- GraphicalAbstract.png 